\title{
Experimental Verification of Optimal Flux Weakening in Surface PM Machines Using Concentrated Windings
}

\author{
Ayman M. EL-Refaie, Student Member, IEEE, Thomas M. Jahns, Fellow, IEEE, \\ Patrick J. McCleer, Member, IEEE, and John W. McKeever
}

\begin{abstract}
Previous analytical work has shown that it is possible to design surface permanent-magnet (SPM) machines using fractional-slot concentrated windings to achieve wide speed ranges of constant power operation by satisfying the optimal flux-weakening condition. This paper presents a 6-kW 36-slot/30-pole concentrated winding prototype SPM machine that has been designed using a closed-form analytical technique developed specifically for this class of machines. Experimental testing of this machine has been carried out to determine its performance capabilities, including flux-weakening operation. Detailed comparisons between analytical, finite-element analysis (FEA), and experimental results are presented, which confirm the ability of fractional-slot concentrated winding SPM machines to achieve their high-speed operating objectives. Important issues including the machine's back EMF voltage at top speed, eddy-current losses in the magnets, and inverter performance are analyzed and discussed in detail.
\end{abstract}

Index Terms-Concentrated, experimental, flux weakening, fractional slot, permanent magnet, surface, synchronous, verification, windings.

\section{INTRODUCTION}

$\mathbf{P}$ AST investigations have shown that wide speed ranges of constant power operation can be achieved using surface permanent-magnet (SPM) machines by introducing fractionalslot concentrated windings to reduce the machine's characteristic current [1]. A closed-form analytical technique has been developed that provides an effective means for rapidly analyzing candidate SPM machine designs using concentrated windings and tuning them to achieve the critical condition for optimal flux weakening [2].

Paper IPCSD-05-098, presented at the 2005 Industry Applications Society Annual Meeting, Hong Kong, October 2-6, and approved for publication in the IEEE TRANSACTIONS ON INDUSTRY APPLICATIONS by the Electric Machines Committee of the IEEE Industry Applications Society. Manuscript submitted for review July 1, 2005 and released for publication December 19, 2005. This work was supported in part by UT-Battelle, LLC, under Subcontract 4000039681, acting under Contract DE-AC05-00OR22725 with the U.S. Department of Energy.

A. M. EL-Refaie was with the Department of Electrical and Computer Engineering, University of Wisconsin, Madison, WI 53706-1691 USA. He is now with the Electrical Machines and Drives Laboratory, GE Global Research Center, Niskayuna, NY 12309-1027 USA (e-mail: elrefaie@ research.ge.com).

T. M. Jahns is with the Department of Electrical and Computer Engineering, University of Wisconsin, Madison, WI 53706-1691 USA (e-mail: jahns@engr.wisc.edu).

P. J. McCleer is with McCleer Power, Inc., Jackson, MI 49203 USA (e-mail: pat@mccleerpower.com).

J. W. McKeever is with the Oak Ridge National Laboratory, Oak Ridge, TN 37831 USA (e-mail: mckeeverjw@ornl.gov).

Digital Object Identifier 10.1109/TIA.2006.870043

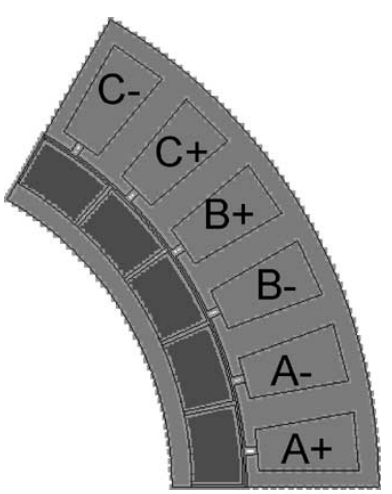

Fig. 1. Basic repeating unit of a prototype SPM machine consisting of six stator slots and five poles.

The ability of designers to use fractional-slot concentrated windings to reduce the SPM machine's characteristic current sufficiently to significantly expand the machine's high-speed operating capabilities has appeared only recently in the technical literature [3]. There are very few examples of experimental machines exhibiting these characteristics that have been tested and then documented in technical forums for the broad professional community [4].

This paper presents a 6-kW 36-slot/30-pole concentrated winding prototype machine that has been designed using this analytical technique. Experimental testing of this machine has been carried out to evaluate its performance capabilities, including flux-weakening operation. Detailed comparisons between analytical, finite-element analysis (FEA), and experimental results are presented in this paper. A wide range of the machine's parameters and operating characteristics are presented to help interested readers assess the strengths and limitations of this class of machines. This discussion will include lessons learned by the authors-some unexpected-during the course of this development effort.

\section{Analytical and FEA Results}

\section{A. Machine Dimensions and Parameters}

A fractional-slot concentrated winding SPM machine has been designed for a wide speed range of constant power operation using the analytical technique presented in [2]. A section of the 36-slot/30-pole machine ( $\operatorname{slot} /$ pole/phase $=2 / 5$ ) is shown in Fig. 1 [1]. The objective of this development effort has 
TABLE I

STATOR DIMENSIONS AND WINDING DATA FOR THE 36-SLOT/30-POLE SPM MACHINE

\begin{tabular}{|c|c|c|c|}
\hline Number of slots & 36 & Number of poles & 30 \\
\hline Number of phases & 3 & Slots/pole/phase & $2 / 5$ \\
\hline Series turns & 108 & Number of turns/coil & 18 \\
\hline Number of coils & 6 & Number of parallel paths & 1 \\
\hline Outer diameter & $280[\mathrm{~mm}]$ & Active length & $60[\mathrm{~mm}]$ \\
\hline Total length & $72[\mathrm{~mm}]$ & Slot fill factor & $35 \%$ \\
\hline Slot opening width & $2[\mathrm{~mm}]$ & Slot bottom width & $10[\mathrm{~mm}]$ \\
\hline Slot top width & $14.6[\mathrm{~mm}]$ & Slot opening height & $3[\mathrm{~mm}]$ \\
\hline Slot height & $25.4[\mathrm{~mm}]$ & Back iron depth & $9[\mathrm{~mm}]$ \\
\hline Tooth width & $11.4[\mathrm{~mm}]$ & Phase resistance & $63[\mathrm{~m} \Omega]$ \\
\hline
\end{tabular}

TABLE II

Rotor DimEnsions For THE 36-SLOT/30-POLE SPM MACHINE

\begin{tabular}{|c|c|c|c|}
\hline Rotor outer radius & $88.6[\mathrm{~mm}]$ & Magnets outer radius & $101.6[\mathrm{~mm}]$ \\
\hline Inner radius & $63.6[\mathrm{~mm}]$ & Air gap thickness & $1[\mathrm{~mm}]$ \\
\hline Magnet depth & $13[\mathrm{~mm}]$ & Magnet span & $11.4^{\circ}[\mathrm{mech}]$ \\
\hline
\end{tabular}

TABLE III

Calculated Inductances For the 36-Slot/30-Pole SPM Machine

\begin{tabular}{|c|c|c|c|}
\hline $\begin{array}{c}\text { Self inductance } \\
\text { (including harmonic } \\
\text { leakage) }\end{array}$ & $225[\mu \mathrm{H}]$ & $\begin{array}{c}\text { Mutual inductance } \\
\text { (including harmonic } \\
\text { leakage) }\end{array}$ & $\sim 0$ \\
\hline $\begin{array}{c}\text { Self slot leakage } \\
\text { inductance }\end{array}$ & $805[\mu \mathrm{H}]$ & $\begin{array}{c}\text { Mutual slot leakage } \\
\text { inductance }\end{array}$ & $\sim 0$ \\
\hline Total self inductance & $1.03[\mathrm{mH}]$ & Net mutual inductance & $\sim 0$ \\
\hline
\end{tabular}

TABLE IV

Calculated Current and Magnet Parameters For the 36-SLOT/30-POLE SPM MACHINE

\begin{tabular}{|c|c|c|c|}
\hline $\begin{array}{l}\text { Magnet Remanent } \\
\text { Flux Density, } \boldsymbol{B}_{\boldsymbol{r}}\end{array}$ & $\begin{array}{c}0.55 \text { [Tesla] } \\
\text { (a) } 100^{\circ} \mathrm{C}\end{array}$ & $\begin{array}{l}\text { Magnet relative } \\
\text { permeability, } \boldsymbol{\mu}_{\boldsymbol{r}}\end{array}$ & 1.22 \\
\hline $\begin{array}{l}\text { RMS PM flux } \\
\text { linkage } \boldsymbol{\Psi}_{\boldsymbol{m}}\end{array}$ & $\begin{array}{c}34.8 \\
{[\mathrm{mWb}-\mathrm{rms}]}\end{array}$ & $\begin{array}{l}\text { RMS Characteristic } \\
\text { Current, } \boldsymbol{I}_{\boldsymbol{c h}}=\boldsymbol{\Psi}_{\boldsymbol{m}} / \boldsymbol{L}_{\boldsymbol{d}}\end{array}$ & $\begin{array}{c}33.8 \\
{[\text { Arms] }}\end{array}$ \\
\hline $\begin{array}{l}\text { RMS Rated } \\
\text { Current, } \boldsymbol{I}_{\boldsymbol{R}}\end{array}$ & 43 [Arms] & $\begin{array}{l}\text { Flux-Weakening } \\
\text { Index } \boldsymbol{F} \boldsymbol{W}=\boldsymbol{I}_{\boldsymbol{c h}} \boldsymbol{I}_{\boldsymbol{R}}\end{array}$ & 0.79 \\
\hline $\begin{array}{c}\text { Copper Current } \\
\text { density }\end{array}$ & $\begin{array}{c}7 \\
{\left[\mathrm{Arms} / \mathrm{mm}^{2}\right]}\end{array}$ & Air Gap Shear stress & $\begin{aligned} & 3.1[\mathrm{psi}] \\
= & 21[\mathrm{kPa}]\end{aligned}$ \\
\hline
\end{tabular}

been to design the SPM machine to achieve a high constant power speed ratio (CPSR) with a target value of 10:1. Using the requirements for an automotive starter/alternator application as a reference point [5], the machine was originally designed as a motor to deliver $4 \mathrm{~kW}$ at a base speed of $600 \mathrm{r} / \mathrm{min}$ and $6 \mathrm{~kW}$ at the top speed of $6000 \mathrm{r} / \mathrm{min}$. All of the analytical results have been verified using FEA (MagNet2D by Infolytica Corporation).

The basic machine unit consisting of six stator slots and five rotor poles is shown in Fig. 1. Key parameters and dimensions for the machine stator and rotor are presented in Tables I and II, respectively. Calculated inductance values for the machine are provided in Table III. Important machine parameters related to the machine's field weakening capabilities, including the rated and characteristic current values, are presented in Table IV. Table $\mathrm{V}$ provides information about the machine's mass, including a breakdown by material.
TABLE V

BREAKDOWN OF MATERIAL MASS FOR THE 36-SLOT/30-POLE SPM MACHINE

\begin{tabular}{|c|c|c|c|}
\hline Copper mass & $2.8[\mathrm{~kg}]$ & Iron mass & $12.6[\mathrm{~kg}]$ \\
\hline Magnet mass & $3.6[\mathrm{~kg}]$ & Total mass & $19[\mathrm{~kg}]$ \\
\hline
\end{tabular}

There are several important observations that can be made from the entries in these tables. Bonded neodymium-ironboron magnets were selected for this prototype machine. The design value of the magnet remanent flux density $B_{r}$ is $0.55 \mathrm{~T}$ with a relative permeability $\mu_{r}$ of 1.22 using the magnet characteristics at $100{ }^{\circ} \mathrm{C}$ in order to include temperature effects and to avoid demagnetization. The reason for choosing bonded magnets with a lower $B_{r}$ value is to minimize the eddy current losses in the magnets, which will be discussed in more detail in Section III. The adoption of such relatively low-strength magnets explains the choice of a relatively large magnet depth of $13 \mathrm{~mm}$.

\section{B. Machine Inductances and Flux-Weakening Operation}

The self and mutual inductance components in Table III (including harmonic leakage inductance) have been calculated using the winding function approach [6]. The slot leakage component is the dominant inductance component, attributable to the adoption of such a large effective air gap length $(14 \mathrm{~mm})$.

It can be seen in Table IV that this machine has a calculated flux-weakening index (FWI) value (defined as the ratio of the machine's characteristic current $I_{c h}$ to its rated current $I_{R}$ ) that is less than unity $(0.79)$ even though the design was initially tuned to achieve unity. This indicates that the machine deviates somewhat from the optimal flux-weakening condition, reflecting an oversight that occurred during the design process. More specifically, slot leakage inductance was initially calculated using classical formulas that are appropriate for ac machines such as induction machines [7]. Unfortunately, such formulas become progressively inaccurate as the machine effective air gap increases, resulting in a calculated total phase selfinductance that is approximately $25 \%$ larger than the target value. It is noted, with some irony, that the design effort to increase the machine's inductance (in order to reduce the characteristic current) was too successful in this case.

Since discovering this error, more accurate two-dimensional (2-D) models have been incorporated into the analytical model for calculating slot leakage inductance in surface SPM machines with large effective air gaps [8]-[10]. Entries in both Tables III and IV are calculated using this improved model. This same model has been used to explore the changes that would be necessary in the machine lamination design to restore the FWI value to unity with the same rated current (43 arms). A parametric study showed that, starting with the existing lamination, increasing the slot opening by $2 \mathrm{~mm}$ (from 2 to $4 \mathrm{~mm}$ ) and reducing the slot opening height by $1 \mathrm{~mm}$ (from 3 to $2 \mathrm{~mm}$ ) changes the design characteristics sufficiently to meet the optimal flux-weakening condition. No other major modifications would be required to achieve this goal. However, a stator using this new lamination design has not been fabricated. 


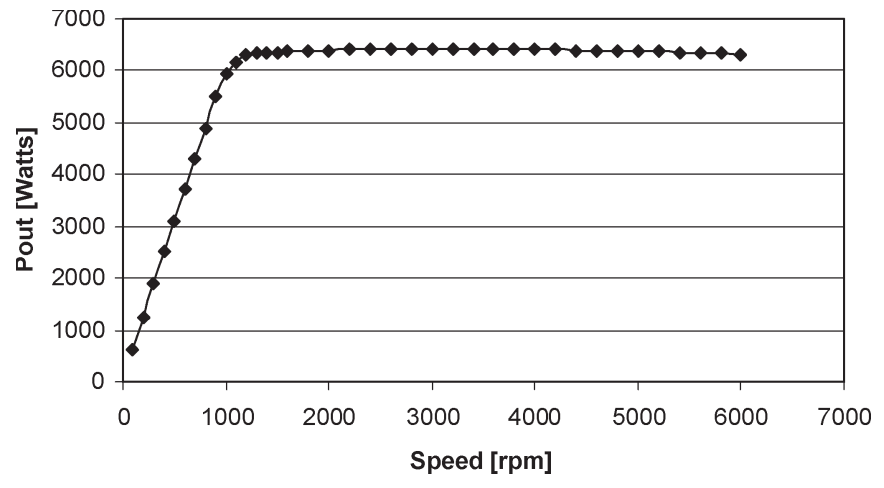

Fig. 2. Calculated power versus speed envelope of the prototype SPM machine.

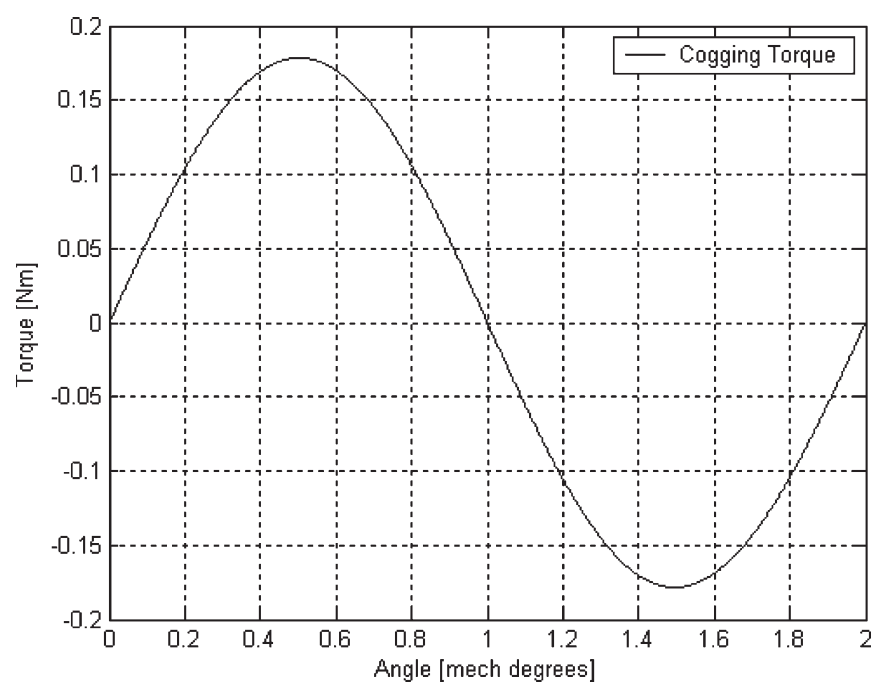

Fig. 3. One cycle of the predicted SPM machine cogging torque.

Updated analytical predictions for the prototype machine with the measured inductance (see Section VI) indicate that the required constant power level of $6 \mathrm{~kW}$ can still be achieved by increasing the dc-bus voltage. The higher bus voltage is necessary for the inverter to supply higher-than-expected voltage drop across the machine's elevated phase reactance.

In this particular case, the dc bus voltage was raised from 126 to $195 \mathrm{~V}$, yielding the calculated power versus speed envelope curve in Fig. 2. This key result will be confirmed by experimental results later in this paper. The important observation is that this prototype machine continues to offer the opportunity to confirm that a wide constant power speed range can be achieved despite its nonoptimal characteristic current value.

\section{Cogging Torque}

Fig. 3 shows one cycle of the predicted cogging torque for the prototype 36-slot/30-pole SPM machine. The predicted peak-to-peak cogging torque amplitude is less than $1 \%$ of the rated torque. This result is consistent with the results presented elsewhere in the literature [1], [11]-[13], showing that cogging torque is one of the significant advantages of using fractionalslot concentrated windings.

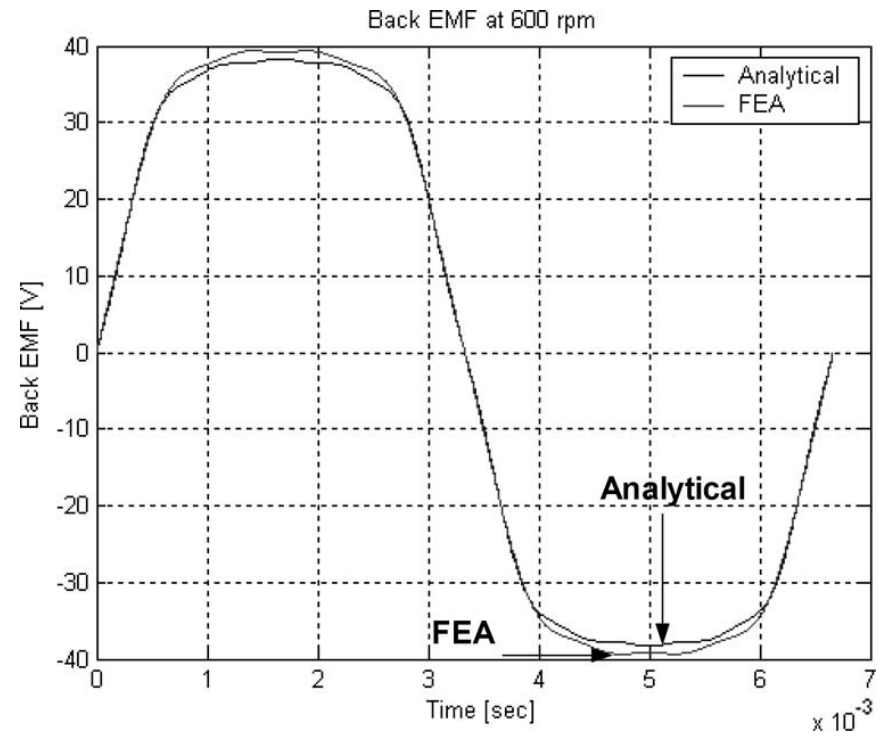

Fig. 4. Overlaid analytical and FEA-predicted phase back-EMF voltage waveforms at $600 \mathrm{r} / \mathrm{min}$.

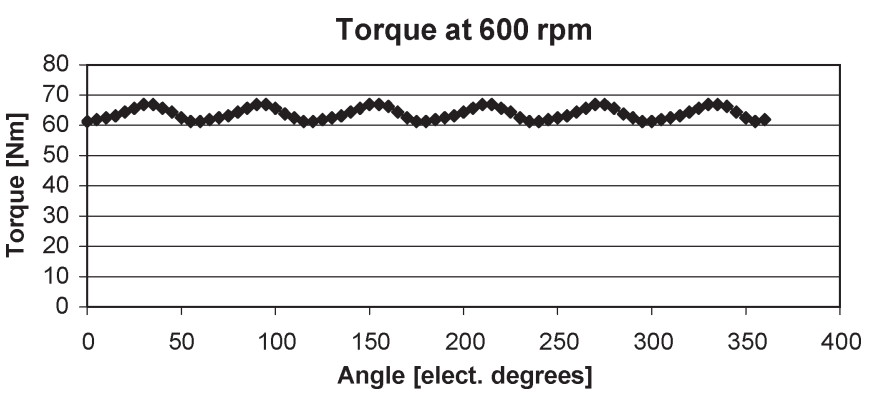

Fig. 5. FEA-predicted machine output torque at $600 \mathrm{r} / \mathrm{min}$ under sinusoidal current excitation.

\section{FEA Results}

Fig. 4 shows overlaid versions of the phase back electromotive-force (EMF) waveform at $600 \mathrm{r} / \mathrm{min}$ using both closed-form analysis and FEA. The excellent match between these two waveforms builds confidence in the accuracy of the analytical model. Although the phase back EMF waveform contains significant harmonic components, the triplen harmonics dominate so that little ripple torque is generated with threephase sinusoidal current excitation. The line-to-line back EMF waveform is almost purely sinusoidal.

The ability of the prototype machine to achieve the desired high CPSR value has also been verified using FEA. Fig. 5 shows the predicted output torque at $600 \mathrm{r} / \mathrm{min}$ over one pole pair using sinusoidal current excitation. The peak-to-peak ripple torque is less than $9 \%$ and the average developed output power is more than $4 \mathrm{~kW}$. The predicted output torque at $6000 \mathrm{r} / \mathrm{min}$ under sixstep voltage excitation is shown in Fig. 6, resulting in output power exceeding $6 \mathrm{~kW}$.

The machine inductance calculated using FEA is $1.16 \mathrm{mH}$, in comparison to a predicted value of $1.03 \mathrm{mH}$ using the improved analytical model. The error is approximately $11 \%$, which is quite acceptable taking into consideration the difficulty of accurately estimating the slot leakage in a machine with such a large effective air-gap length. 


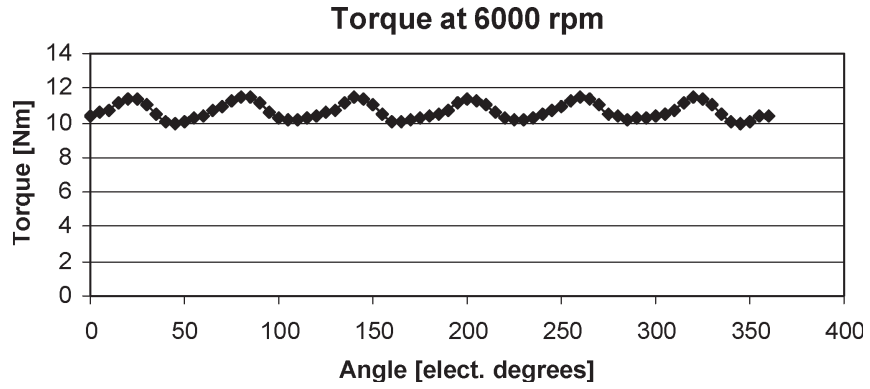

Fig. 6. FEA-predicted machine output torque at $6000 \mathrm{r} / \mathrm{min}$ under six-step voltage excitation.

\section{Rotor MAgnet Losses}

Since the fractional-slot concentrated winding produces an air gap magnet flux distribution that is rich in spatial subharmonics and higher-order harmonics [1], one of the key performance issues in such machines is the resulting eddy current losses induced in the magnets and rotor core [14].

In this prototype machine, the rotor core is laminated in order to minimize eddy-current losses. The magnets selected for this machine are bonded $\mathrm{NdFeB}$ magnets that have a resistivity higher than $20 \mu \Omega \cdot \mathrm{m}$. Since bonded magnets have significantly higher resistivity than sintered magnets $(0.5-1.5 \mu \Omega \cdot \mathrm{m})$, the choice of bonded magnets is important for minimizing the magnet losses in this machine.

The tradeoffs associated with selecting the lower strength bonded magnet material include an increase in magnet mass (due to the increase in magnet depth) and a slight increase in the machine rated current for the same rated torque. Both of these factors contribute to a slight decrease in the machine's specific torque density (newton meter per kilogram) compared to a comparable SPM machine designed using high-strength sintered magnets.

The magnet losses have been evaluated using both closedform analysis [14] and FEA. A good match has been achieved between the predicted losses using both techniques. The predicted average magnet loss at $6000 \mathrm{r} / \mathrm{min}$ is approximately $230 \mathrm{~W}$, which is less than $4 \%$ of the machine output at this speed. This result is an important factor in the machine's ability to achieve high machine efficiency (over 90\%) at high speeds. The $6000 \mathrm{r} / \mathrm{min}$ operating point represents the highest magnet loss since losses are proportional to the square of the speed [14].

An option for further reducing eddy current losses is segmentation of the magnets along the rotor periphery. This option has been investigated both analytically and using FEA, and the results are summarized in Fig. 7. This figure confirms the expectation that the dominant spatial subharmonics (in this case the fundamental and the seventh) are the primary sources of magnet losses. This figure also shows that segmentation has a significant effect on reducing the loss components generated by these dominant subharmonics.

\section{INVERTER PERformanCE}

The high pole number of this prototype (30) raises some concerns regarding inverter performance, particularly at high speeds. Performance characteristics of the inverter power stage

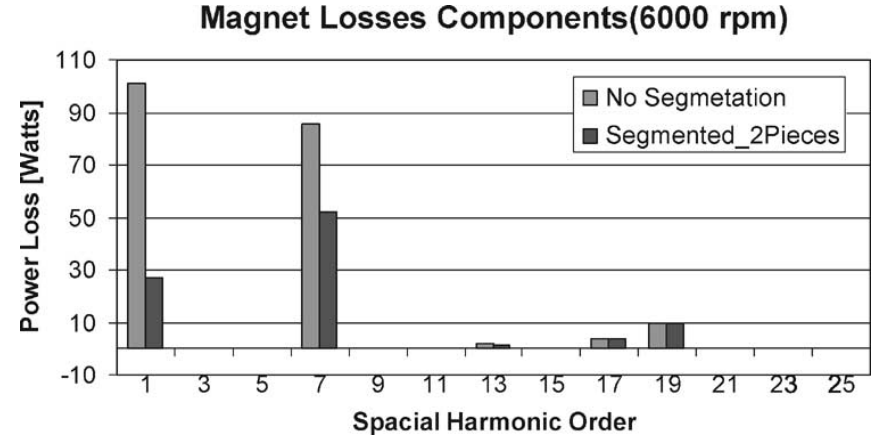

Fig. 7. Predicted harmonic breakdown of magnet losses at $6000 \mathrm{r} / \mathrm{min}$ and the effect of segmentation.

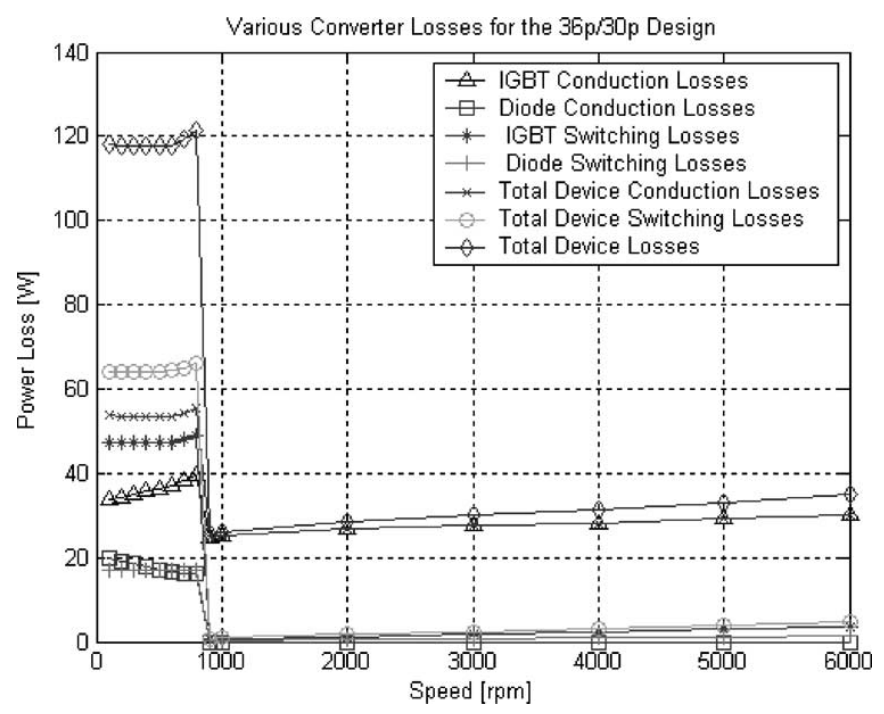

Fig. 8. Predicted IGBT inverter loss components as a function of rotor speed along the machine capability envelope.

while exciting the prototype SPM machine have been calculated, including an investigation of the impact of the machine's high pole number on converter losses [15], [16].

Since the minimum dc link voltage is approximately $200 \mathrm{~V}$, insulated gate bipolar transistors (IGBTs) were selected for the inverter switches. It is assumed that the inverter operates in pulsewidth-modulation (PWM) mode with a switching frequency of $20 \mathrm{kHz}$ at all rotor speeds below the adjusted base speed of $800 \mathrm{r} / \mathrm{min}$, while six-step voltage excitation is applied at all higher speeds. As a result, the switching frequency equals the machine excitation frequency during high-speed operation.

The IGBT module used for this analytical exercise is manufactured by Fairchild Semiconductor [17] using 600-V/75-A IGBTs. Fig. 8 shows the predicted inverter loss components as a function of speed along the machine's capability envelope, while Fig. 9 shows the corresponding inverter efficiency. It can be seen that switch conduction losses dominate at high speeds, and the inverter efficiency exceeds $95 \%$ throughout the constant power operating regime. Below the base speed, the switching losses are more prominent since the converter is still operating in its PWM mode.

Another performance issue determined by the convertermachine interface is the amplitude of the phase current ripple. 


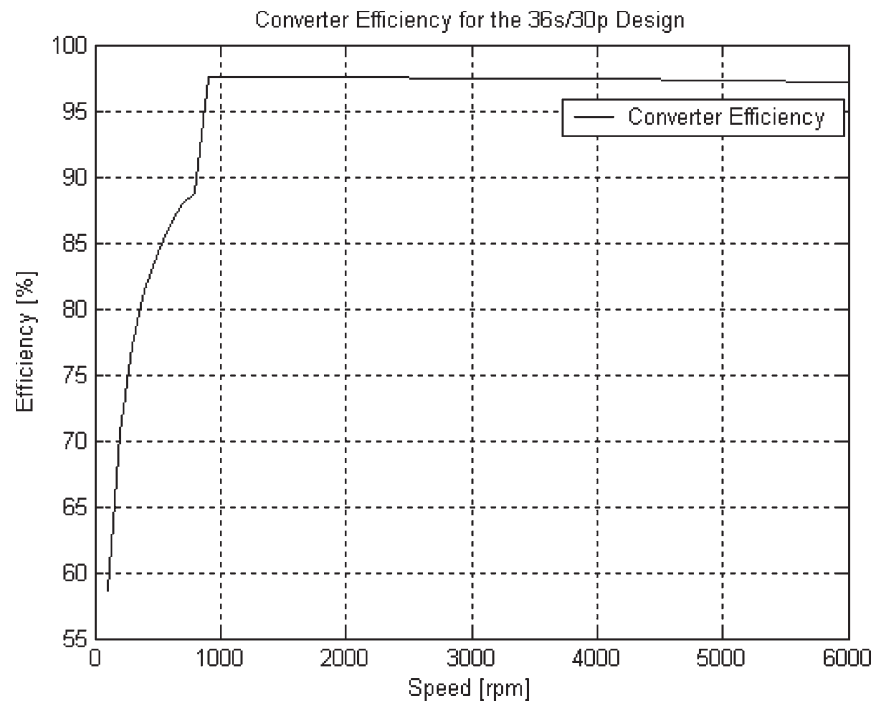

Fig. 9. Predicted inverter efficiency along the machine capability envelope as a function of rotor speed.

The maximum peak-to-peak current ripple amplitude can be estimated as [18]

$$
I_{\text {ripple }}=\frac{V_{d c} T_{s}}{4 L_{\sigma}}
$$

where $L_{\sigma}$ is the machine transient inductance and $T_{s}$ is the PWM switching period. This maximum ripple occurs when the machine phase is excited by a symmetrical square-wave voltage waveform (duty cycle $=0.5$ ) with period $T_{s}$ and amplitude $\left(V_{d c} / 2\right)$.

For SPM machine designs with concentrated windings, $L_{\sigma}$ is equal to the machine phase self-inductance, for many configurations inluding the 36-slot/30-pole combination used for the experimental machine because the mutual phase inductance is very low. For the prototype machine with a dc-bus voltage, $300 \mathrm{~V}$, and $20-\mathrm{kHz}$ switching frequency, the predicted maximum current ripple is approximately $3 \mathrm{~A}$.

This value has been confirmed experimentally as shown in Figs. 10 and 11. Fig. 10 shows the machine phase current at $600 \mathrm{r} / \mathrm{min}$ while Fig. 11 expands the interval where the maximum ripple occurs near the peak current. It can be seen that the current is quite sinusoidal and the peak-to-peak ripple is in the vicinity of $3 \mathrm{~A}$, as predicted. This ripple amplitude represents approximately $5 \%$ of the peak phase current, which is quite acceptable. Additional calculations not presented here indicate that this low ripple contributes very little additional copper losses [19].

\section{PRototype Machine Fabrication AND TEST CONFIGURATION}

This section provides information about the prototype machine fabrication and test configuration. Fig. 12 shows the laminated stator core and the concentrated winding coils. The stator lamination stack is held together using cleats. The thin back iron made possible by the high number of poles is also

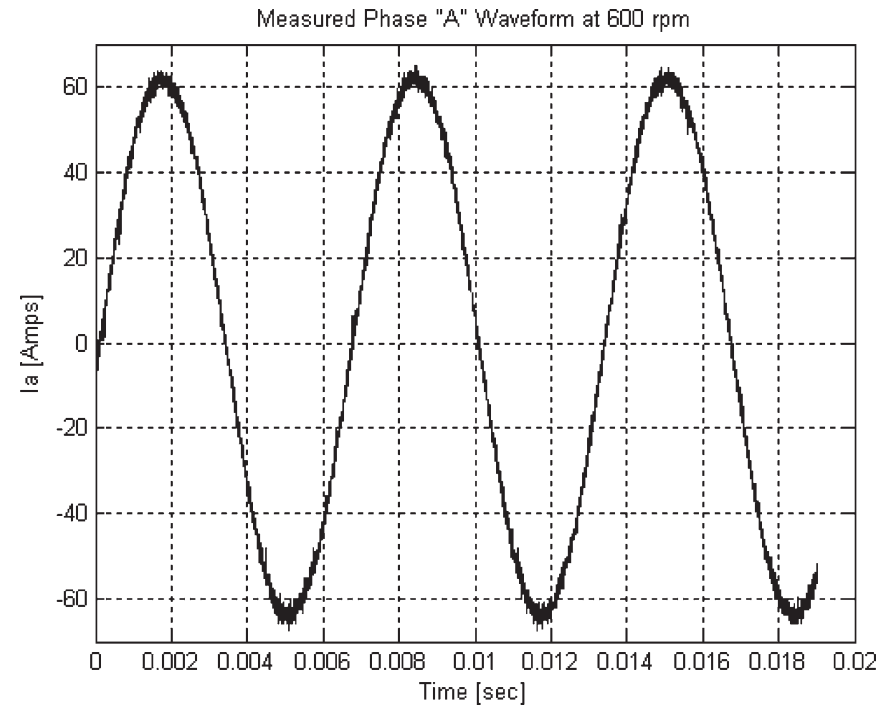

Fig. 10. Measured phase current at $600 \mathrm{r} / \mathrm{min}$ with rated current operation. $V_{\mathrm{dc}}=300 \mathrm{~V}$.

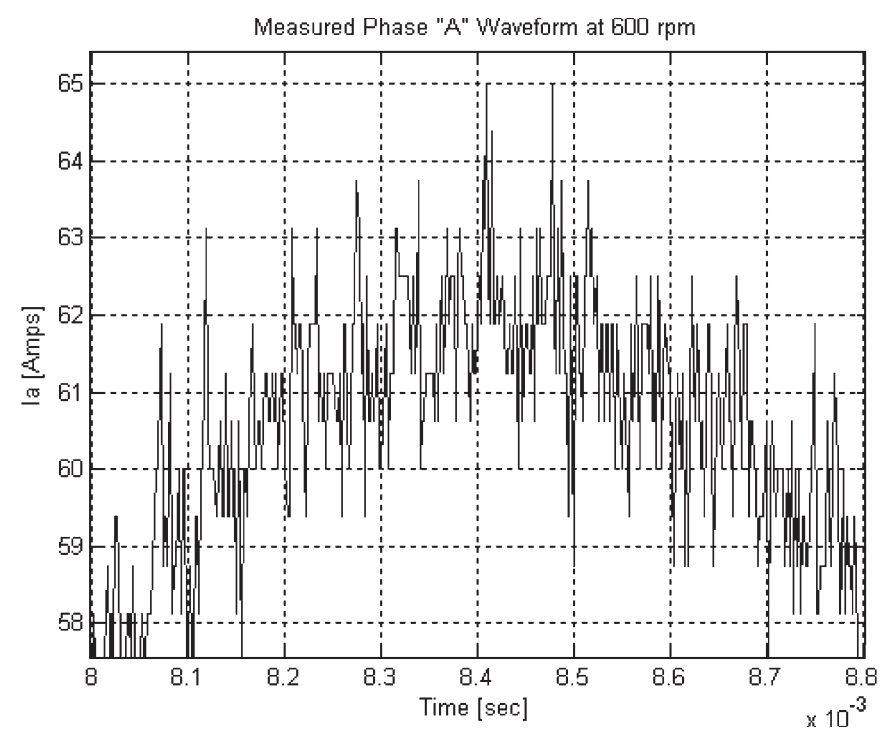

Fig. 11. Expanded view of measured phase current at $600 \mathrm{r} / \mathrm{min}$ showing peak ripple.

evident. Fig. 13 highlights the concentrated stator windings and their short nonoverlapping end turns.

Fig. 14 shows the rotor assembly during fabrication including the aluminum inner hub, the rotor laminated core, and three of the assembled magnet poles. The rotor laminations are held together using axial bolts. The magnets are positioned on the rotor surface with the aid of small location guides on the periphery of the rotor laminations. The magnets are then fixed in place using glue and two layers of fiberglass tape. Each pole is divided axially into three magnet pieces due to magnet manufacturing limitations. Fig. 15 shows the rotor after all the magnets were mounted.

Figs. 16 and 17 show two different views of the prototype machine. In these figures, the stator has been installed inside the aluminum C-Core open frame. The rotor has also been mounted on the shaft and the bearings are visible in Fig. 18. 


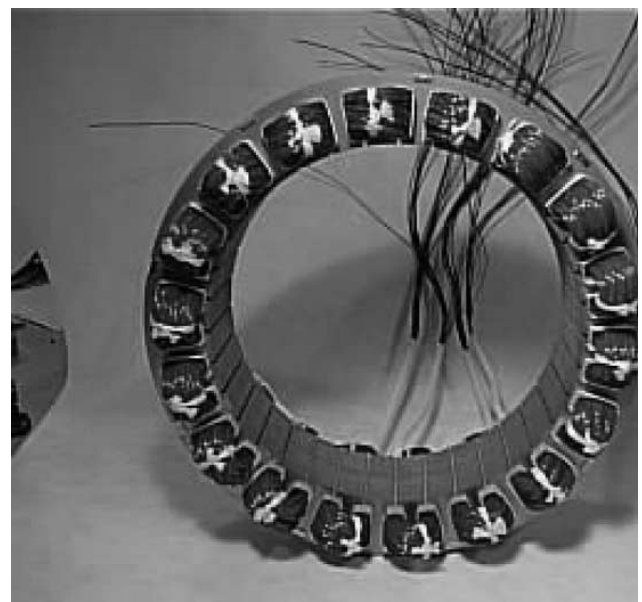

Fig. 12. Prototype machine stator core and concentrated stator windings.

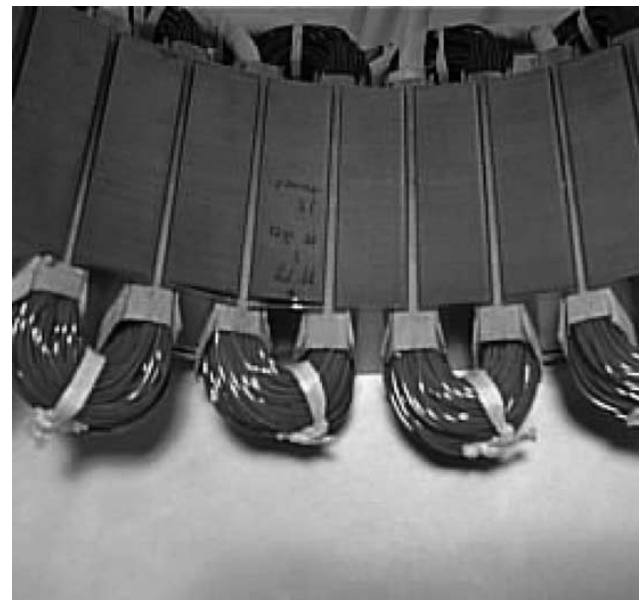

Fig. 13. Close-up view of concentrated winding with nonoverlapping end turns.

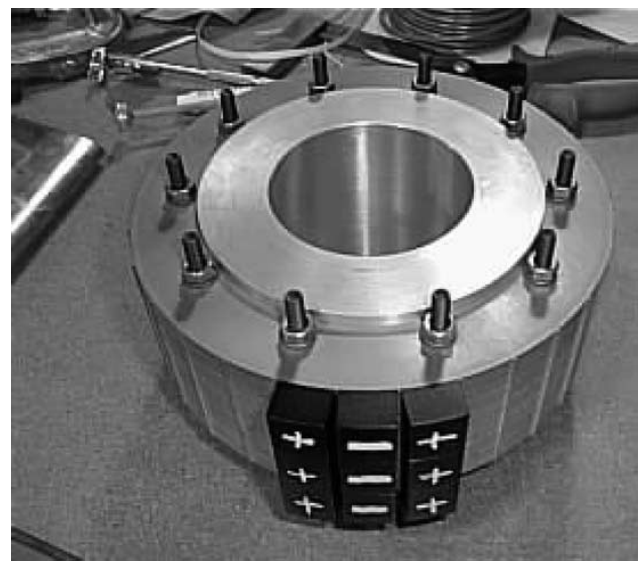

Fig. 14. Rotor magnets during the assembly process.

A schematic of the test configuration is shown in Fig. 18 [20]. The prototype 6-kW SPM machine is coupled to a flexible fourquadrant dynamometer that uses a $25-\mathrm{kW} 6000-\mathrm{r} / \mathrm{min}$ induction machine. An in-line torque transducer is used to measure the torque and speed. Each machine is excited by a 50-hp Danfoss drive controlled using a dSpace 1103 board.

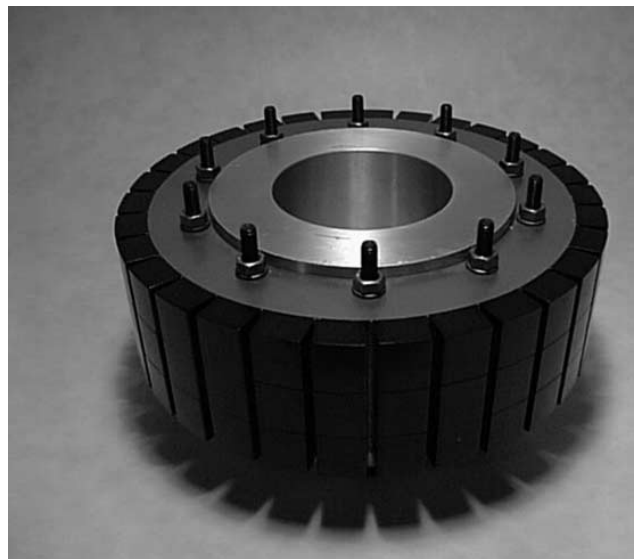

Fig. 15. Rotor assembly showing hub, laminations, and mounted magnets.

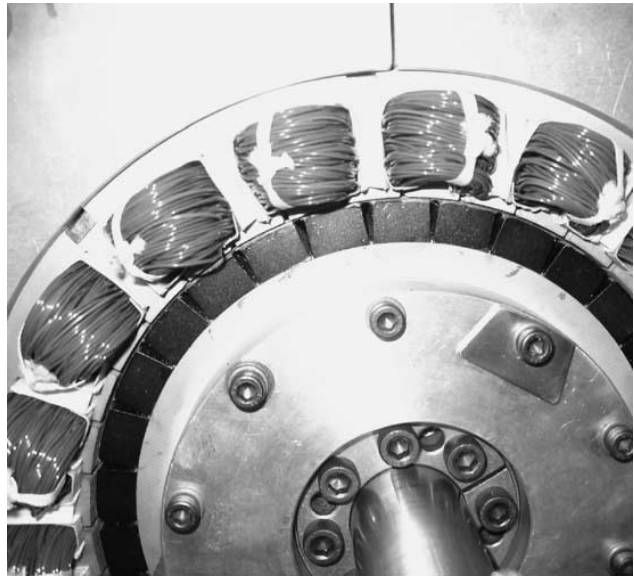

Fig. 16. Close-up view of the machine after stator-rotor assembly in frame.

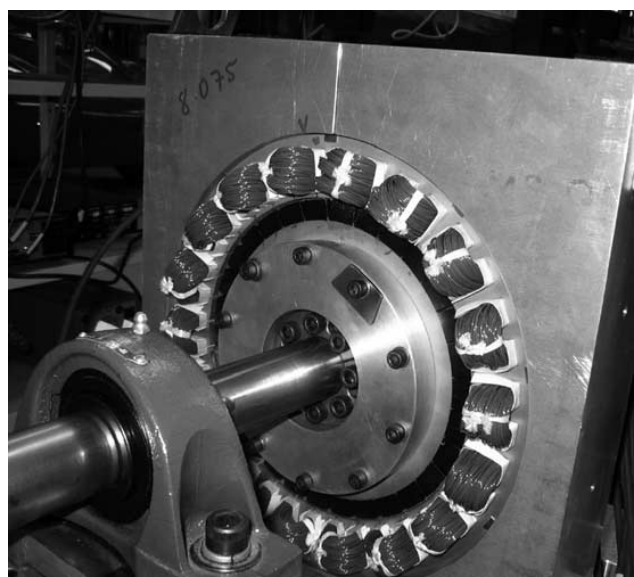

Fig. 17. End view of the machine after assembly, including bearings.

\section{EXPERIMENTAL RESULTS}

This section provides a summary of the key experimental results, including parameter measurements and comparisons between the experimental results and both closed-form analytical and FEA results. 


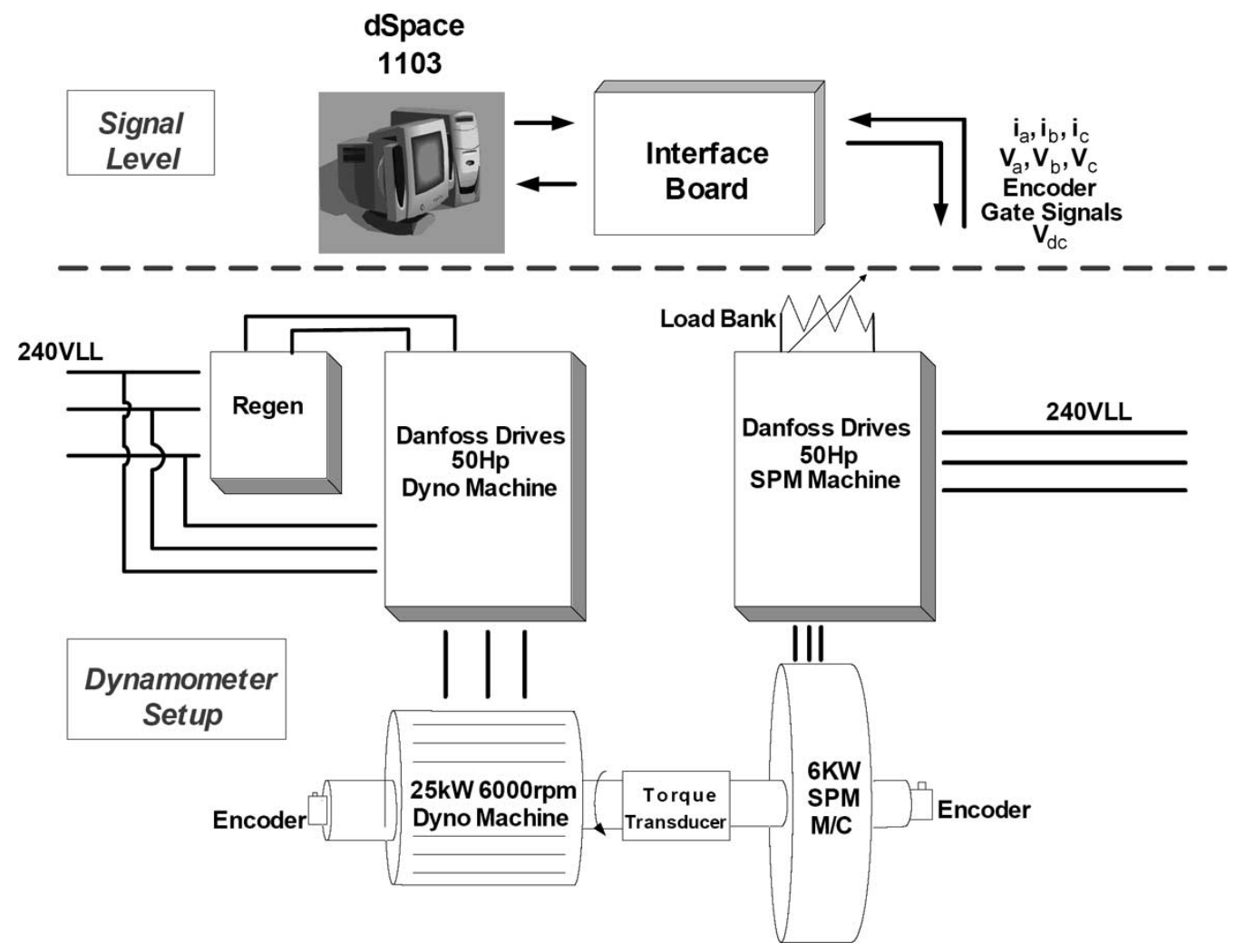

Fig. 18. Dynamometer test configuration for prototype SPM machine [20].

\section{A. Machine Parameters}

The measured value of the stator phase resistance at room temperature is approximately $71 \mathrm{~m} \Omega, 11 \%$ higher than the analytical prediction of $63 \mathrm{~m} \Omega$. The main reason for this discrepancy is the difference between the $40 \%$ copper slot fill factor used in the calculations and the actual achieved value of approximately $35 \%$.

The measured phase inductance is approximately $1.3 \mathrm{mH}$, which is higher than both the updated analytical prediction $(1.03 \mathrm{mH})$ and the FEA prediction $(1.16 \mathrm{mH})$. Sources of this difference include the end leakage inductance that is not included in either the two-dimensional (2-D) FEA or the analytical predictions, and remaining inaccuracies in the slot leakage inductance estimate.

Fig. 19 shows the measured phase- $A$ magnet flux-linkage compared to both analytical and FEA results, demonstrating very good matches in both cases. The experimental flux linkage is slightly higher than either of the analytical results due to the fact that the actual magnet $B_{r}$ value of the received magnets is approximately $0.59 \mathrm{~T}$ at room temperature compared to the magnet $B_{r}$ design value of $0.55 \mathrm{~T}$ at $100{ }^{\circ} \mathrm{C}$.

Fig. 20 shows the measured phase- $A$ back-EMF voltage compared to both closed-form analytical and FEA results, again demonstrating very good matches. As in the case of flux linkages, the slightly elevated amplitude of the experimental back EMF is attributable to the difference in $B_{r}$.

The measured harmonic spectra of the experimental back EMF waveform are shown in Fig. 21. It can be seen that the measured back EMF waveform consists almost entirely of a fundamental and a third harmonic component. The analytical

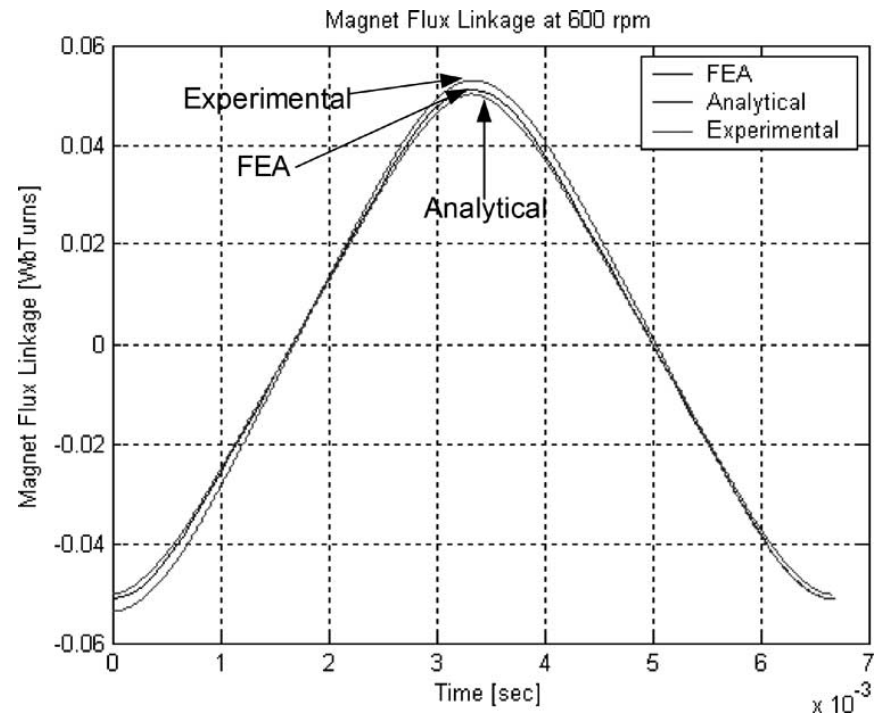

Fig. 19. Comparison of calculated and measured phase- $A$ magnet fluxlinkage waveforms.

back EMF waveform includes some higher order harmonic components in addition to the fundamental and third harmonic components. This favorable result suggests that the prototype machine will have a lower torque ripple than predicted. With a floating neutral winding connection, the third harmonic component in the back-EMF voltage is prevented from contributing any ripple torque since triplen harmonic currents cannot flow.

The small difference between measured and predicted backEMF harmonic spectra can be explained by comparing the magnets shape used in the analytical model shown in Fig. 22 


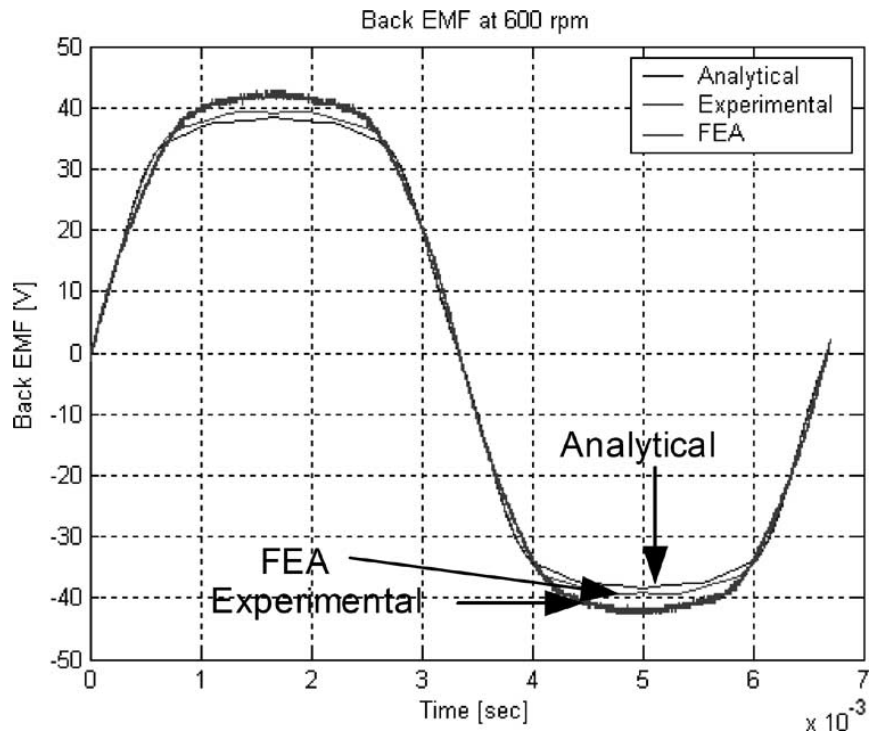

Fig. 20. Comparison of calculated and measured phase- $A$ back-EMF voltage waveforms at $600 \mathrm{r} / \mathrm{min}$.

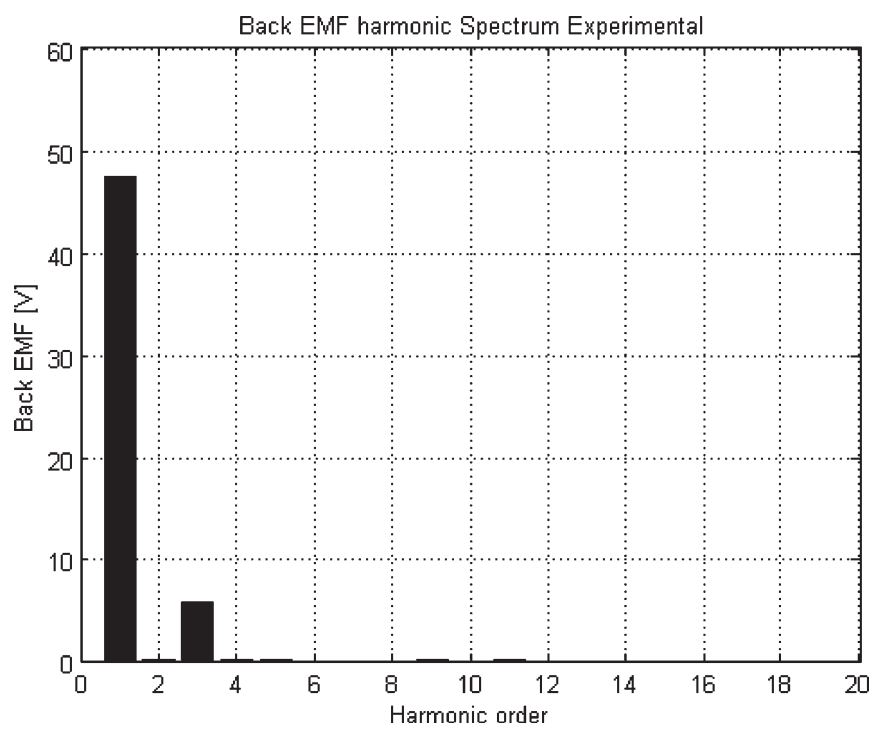

Fig. 21. Harmonic spectrum of the measured phase- $A$ back-EMF voltage waveform at $600 \mathrm{r} / \mathrm{min}$.

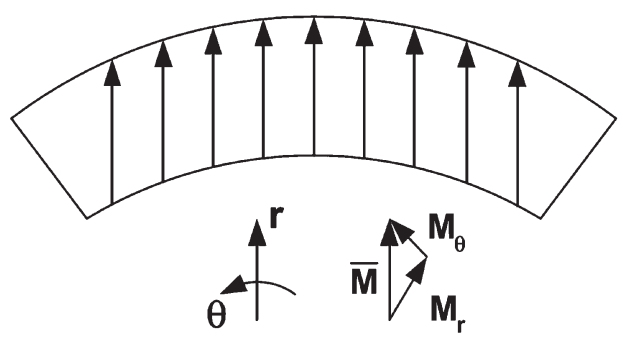

Fig. 22. Shape of the magnets used in the analytical model.

[21] and the actual magnet shape used in the prototype machine shown in Fig. 23. While parallel magnetization is used in both cases, the edges of the actual magnet are slightly tapered compared to the assumed analytical shape due to manufacturing constraints. This tapered magnet shape is responsible for the

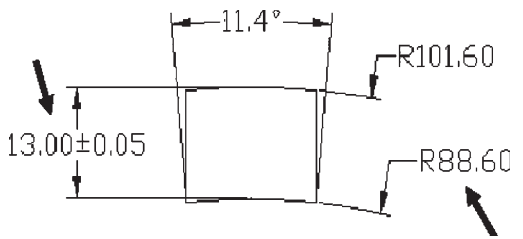

Fig. 23. Actual shape of the magnets used in the prototype machine.

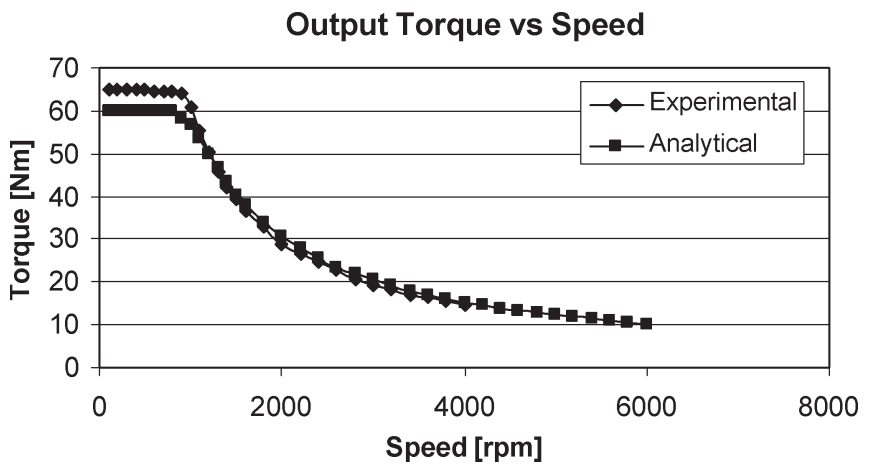

Fig. 24. Comparison of the measured and calculated machine torque versus speed envelopes.

near absence of higher order harmonics in the measured back EMF voltage waveform.

\section{B. Machine Torque and Power Versus Speed Envelopes}

As discussed in Section II, the dc-bus voltage was raised from its original design value of $126-195 \mathrm{~V}$ as a result of the higher-than-expected phase inductance. This higher bus voltage makes it possible to demonstrate that the machine can achieve a wide speed range of constant power operation at the $6-\mathrm{kW}$ level.

For the test results reported here, the bus voltage was raised to a somewhat higher value than the minimum required value of $195 \mathrm{~V}$, and the tests were conducted with the machine operating continuously in PWM mode in order to simplify control issues. The torque/power envelope tests were carried out by adjusting the synchronous-frame $i_{d}$ and $i_{q}$ current values to develop the desired torque/power within the targeted phase voltage limit of $87.8 \mathrm{Vrms}$ (fundamental). This phase voltage corresponds to a dc-link bus voltage of $195 \mathrm{~V}$ (ignoring switch voltage drops) with six-step voltage excitation (i.e., $195 *(\sqrt{2} / \pi)=$ 87.8 Vrms).

Comparisons of the measured and updated analytical machine torque versus speed envelopes and the corresponding power versus speed envelopes are shown in Figs. 24 and 25, respectively. The envelope curves in Figs. 24 and 25 show that there is a very good match between the measured and analytical results up to the maximum test speed of $4000 \mathrm{r} / \mathrm{min}$. These results are very significant since they confirm that the prototype machine has achieved a wide speed range of constant power operation (approximately 5:1, to date).

At the time of writing, no tests have been carried out above $4000 \mathrm{r} / \mathrm{min}$ to complete testing at lower speeds before exposing the rotor to higher structural stresses. All available evidence 


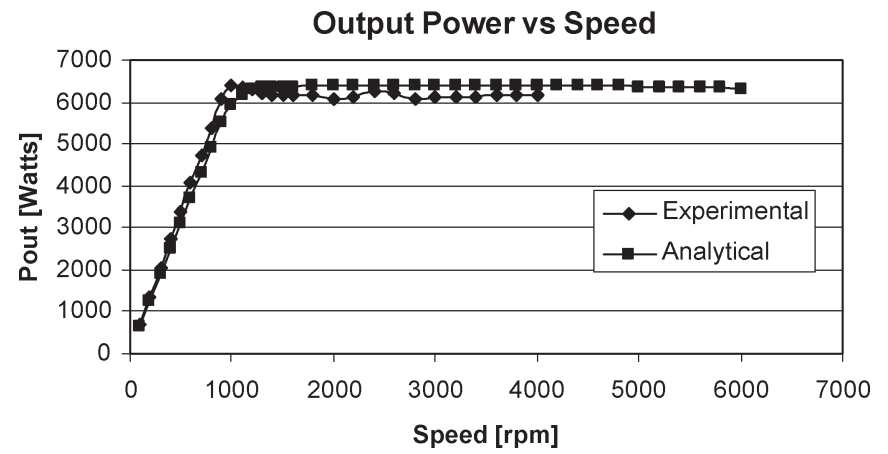

Fig. 25. Comparison of the measured and predicted machine power speed envelopes.

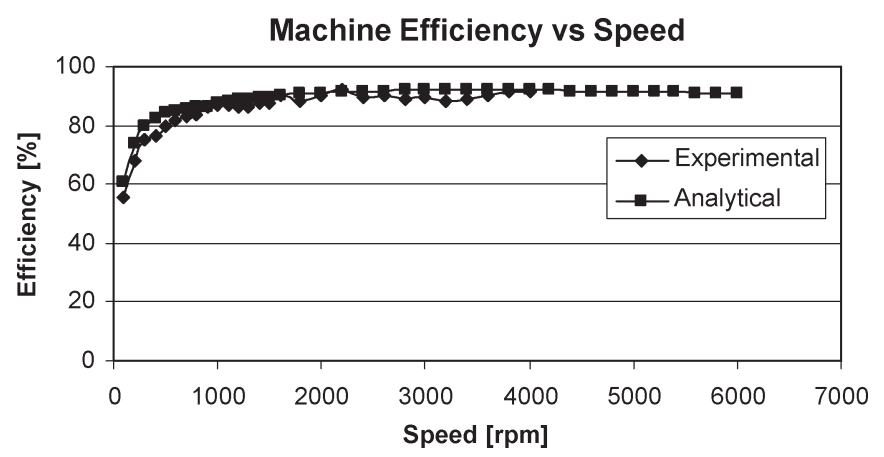

Fig. 26. Comparison of the measured and calculated machine efficiency versus speed envelopes.

suggests that the machine will be able to demonstrate higher CPSR values before testing is completed.

The results in Fig. 24 show that the measured torque is slightly higher than predicted at lower speeds for the same stator current. This is consistent with the higher value of magnet $B_{r}$ in the prototype machine, as previously discussed.

\section{Machine and Inverter Efficiency Versus Speed Envelopes}

Fig. 26 shows a comparison of the measured and calculated machine efficiency versus speed along the maximum torque/power envelope. Updated analytical predictions and measured results agree very closely over the entire tested speed range up to $4000 \mathrm{r} / \mathrm{min}$. The measured prototype machine efficiency is higher than $90 \%$ at elevated speeds, confirming successful suppression of the eddy current losses in the magnets and rotor core that are generated by the significant air gap subharmonic field components. This is very significant since these losses have been considered to be one of the key potential obstacles to using fractional-slot concentrated windings for high-speed operation.

It is worth noting that the machine efficiency at each torque-speed operating point is insensitive to the series/parallel configuration of the stator coils that make up each phase provided that the current in each individual coil stays the same. For example, the six series coils that make up each stator phase winding in this prototype SPM machine could be reconnected to operate from a lower dc bus voltage appropriate

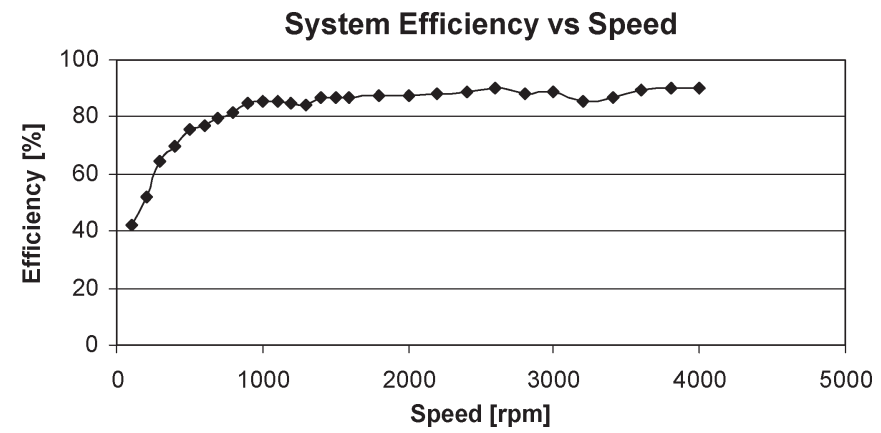

Fig. 27. Measured machine-plus-inverter system efficiency versus speed envelope.

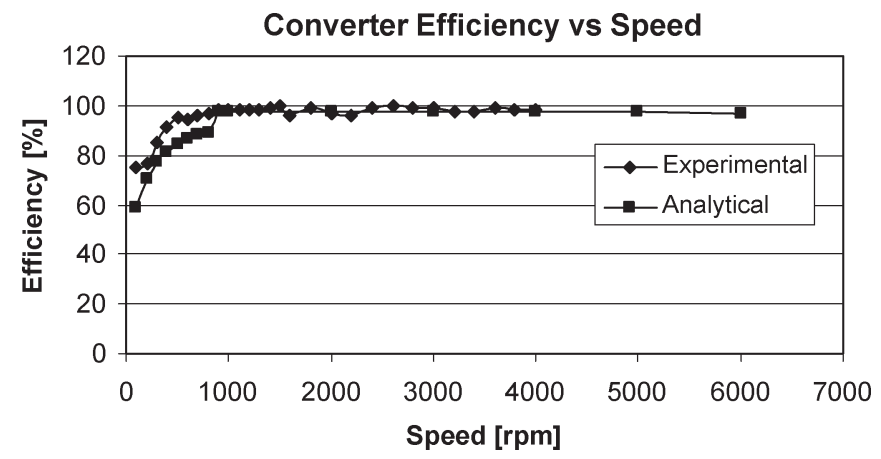

Fig. 28. Comparison of the measured and calculated inverter efficiency versus speed envelopes.

for automotive applications (e.g., $42 \mathrm{Vdc}$ ) without degrading machine efficiency.

Fig. 27 shows the measured machine-plus-inverter system efficiency versus speed envelope. The inverter input power was determined using measurements of the dc bus voltage and current. The output power was determined by measuring the machine output torque and speed. This curve shows that the machine-plus-inverter efficiency is nearly $90 \%$ over most of the speed range up to $4000 \mathrm{r} / \mathrm{min}$, confirming the opportunities provided by the concentrated winding SPM machine to achieve high drive efficiency values.

Using the measured machine and system efficiency values presented in the preceding two figures, the "measured" converter efficiency has been extracted and compared to the analytical predictions in Fig. 28. Consistent with the results in Figs. 26 and 27, the predicted and measured inverter efficiency values agree very well, reaching values in the vicinity of $98 \%$ at high speeds.

\section{CONCLUSION}

A 6-kW 36-slot/30-pole fractional-slot concentrated winding SPM machine has been successfully designed, fabricated, and tested to achieve a wide speed range of constant power operation. Closed-form analysis and FEA have been used extensively during the design process. Important machine and drive performance issues including eddy current losses in the magnets and inverter losses have been analyzed in detail.

Experimental results from the prototype SPM machine were used to improve the accuracy of the closed-form analytical 
model for machine inductance calculations. Comparisons between machine parameters and performance derived from the improved analytical model, FEA, and the experimental tests have demonstrated very good agreement.

The test results have convincingly demonstrated the SPM machine's ability to deliver wide speed ranges of constant power operation as well as high machine efficiency. These experimental verification results are intended to assist PM machine and drive designers who are interested in considering SPM machines for applications such as electric traction that have generally been considered beyond its reach in the past.

\section{ACKNOWLEDGMENT}

The authors thank Prof. D. W. Novotny for many valuable technical discussions. The authors also thank the Wisconsin Electric Machines and Power Electronics Consortium for use of its facilities.

\section{REFERENCES}

[1] A. M. EL-Refaie and T. M. Jahns, "Optimal flux weakening in surface PM machines using concentrated windings," IEEE Trans. Ind. Appl., vol. 41, no. 3, pp. 790-800, May/Jun. 2005.

[2] — - "Analysis of surface permanent magnet machines equipped with concentrated windings," IEEE Trans. Energy Convers., to be published.

[3] J. Cros, J. R. Figueroa, and P. Viarouge, "BLDC motors with surface mounted PM rotor for wide constant power operation," in Conf. Rec. IEEE-IAS Апnи. Meeting, Salt Lake City, UT, Oct. 2003, vol. 3, pp. 1933-1940.

[4] F. Magnussen, P. Thelin, and C. Sadarangani, "Performance evaluation of permanent magnet synchronous machines with concentrated and distributed windings including the effect of field weakening," in Proc. 2nd IEE Int. Conf. Power Electronics, Machines and Drives (PEMD), Edinburgh, U.K., Mar./Apr. 2004, vol. 2, pp. 679-685.

[5] E. C. Lovelace, T. M. Jahns, J. L. Kirtley, Jr., and J. H. Lang, "An interior PM starter/alternator for automotive applications," in Proc. Int. Conf. Electrical Machines (ICEM), Istanbul, Turkey, 1998, vol. 3, pp. $1802-1808$.

[6] D. W. Novotny and T. A. Lipo, Vector Control and Dynamics of AC Drives. Oxford, U.K.: Clarendon, 1998.

[7] T. A. Lipo, Introduction to AC Machine Design. Madison, WI: Wisconsin Power Electronics Research Center, Univ. Wisconsin, 1996.

[8] Z. Q. Zhu, D. Howe, and T. S. Birch, "Calculation of winding inductances of brushless motors with surface-mounted permanent magnets," in Proc. Int. Conf. Electrical Machines (ICEM), Paris, France, 1994, pp. 327-332.

[9] Z. Q. Zhu and D. Howe, "Winding inductances of brushless machines with surface-mounted magnets," in Proc. Int. Electric Machines and Drives Conf. (IEMDC), Milwaukee, WI, May 1997, pp. WB2/2.1-WB2/2.3.

[10] Z. Q. Zhu, D. Howe, and J. K. Mitchell, "Magnetic field analysis and inductances of brushless DC machines with surface-mounted magnets and non-overlapping stator windings," IEEE Trans. Magn., vol. 31, no. 3, pp. 2115-2118, May 1995.

[11] J. Cros and P. Viarouge, "Synthesis of high performance PM motors with concentrated windings," IEEE Trans. Energy Convers., vol. 17, no. 2, pp. 248-253, Jun. 2002.

[12] F. Magnussen and C. Sadarangani, "Winding factors and joule losses of permanent magnet machines with concentrated windings," in Proc. Int. Electric Machines and Drives Conf. (IEMDC), Madison, WI, Jun. 2003, vol. 1, pp. 333-339.

[13] Z. Q. Zhu and D. Howe, "Influence of design parameters on cogging torque in permanent magnet machines," IEEE Trans. Energy Convers., vol. 15 , no. 4, pp. 407-412, Dec. 2000.

[14] K. Atallah, D. Howe, P. H. Mellor, and D. A. Stone, "Rotor loss in permanent-magnet brushless AC machines," IEEE Trans. Ind. Appl., vol. 36, no. 6, pp. 1612-1618, Nov./Dec. 2000.

[15] F. Casanellas, "Losses in PWM inverters using IGBTs," Proc. Inst. Elect. Eng.-Electr. Power Appl., vol. 141, no. 5, pp. 235-239, Sep. 1994.

[16] M. H. Bierhoff and F. W. Fuchs, "Semiconductor losses in voltage source and current source IGBT converters based on analytical derivation," in
Proc. IEEE 35th Power Electronics Specialists Conf. (PESC), Aachen, Germany, Jun. 2004, vol. 4, pp. 2836-2842.

[17] FMG1G75US60H-Molding Type IGBT Module, Fairchild Semiconductor Data Sheet, South Portland, ME, 2002.

[18] J. W. Kolar, T. W. Wolbank, and M. Schrodl, "Analytical calculation of the RMS current stress on the DC link capacitor of voltage DC link PWM converter systems," in Proc. 9th Int. Conf. Electrical Machines and Drives (EMD), Canterbury, U.K., 1999, pp. 81-89.

[19] A. H. Hava, "Carrier based PWM-VSI drives in the overmodulation region," Ph.D. dissertation, Dept. Elect. Comput. Eng., Univ. Wisconsin, Madison, 1998.

[20] J. Wai, "High performance testbed for an automotive direct-drive starter/alternator synchronous machine," M.S. thesis, Dept. Elect. Comput. Eng., Univ. Wisconsin, Madison, 2002.

[21] Z. Q. Zhu, D. Howe, and C. C. Chan, "Improved analytical model for predicting the magnetic field distribution in brushless permanent-magnet machines," IEEE Trans. Magn., vol. 38, no. 1, pp. 229-238, Jan. 2002.

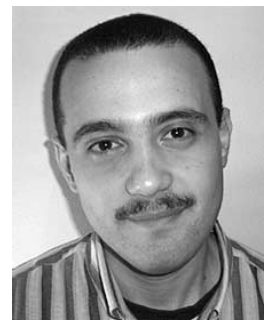

Ayman M. EL-Refaie (S'95) received the B.Sc. and M.Sc. degrees in electrical power engineering from Cairo University, Cairo, Egypt, in 1995 and 1998, respectively, and the M.Sc. and Ph.D. degrees in electrical engineering from the University of Wisconsin, Madison, in 2002 and 2005, respectively.

Between 1995-1998, he was an Assistant Lecturer at Cairo University and the American University in Cairo. Between 1999-2005, he was a Research Assistant at the Wisconsin Electric Machines and Power Electronics Consortium, University of Wisconsin, Madison. He is currently an Electrical Engineer at the Electrical Machines and Drives Laboratory, GE Global Research Center, Niskayuna, NY. His interests include electrical machines and drives.

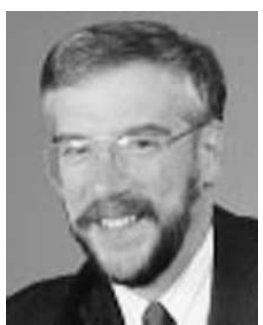

Thomas M. Jahns (M'79-SM'91-F'93) received the B.S. and M.S. degrees in 1974 and the Ph.D. degree in 1978 from Massachusetts Institute of Technology (MIT), Cambridge, all in electrical engineering.

Prior to joining the University of Wisconsin, Madison, he was with GE Corporate Research and Development (now GE Global Research Center), Schenectady, NY, for 15 years, where he pursued new power electronics and motor drive technology in a variety of research and management positions. Between 1996-1998, he conducted a research sabbatical at MIT, where he directed research activities in the area of advanced automotive electrical systems and accessories as Co-Director of an industry-sponsored automotive consortium. In 1998, he was a Professor in the Department of Electrical and Computer Engineering, University of Wisconsin, where he is also the Associate Director of the Wisconsin Electric Machines and Power Electronics Consortium. His research interests include permanent-magnet synchronous machines for a variety of applications ranging from high-performance machine tools to low-cost appliance drives.

Dr. Jahns served as President of the IEEE Power Electronics Society (PELS) (1995-1996) and as Division II Director of the IEEE Board of Directors (2001-2002). He has been recognized as a Distinguished Lecturer by the IEEE Industry Applications Society (IAS) during 1994-1995 and by IEEE-PELS during 1998-1999. He was awarded the William E. Newell Award by the IEEEPELS in 1999 and was the recipient of the 2005 IEEE Nikola Tesla Award. 


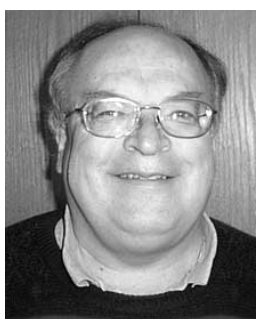

Patrick J. McCleer (M'78) received the B.S. degree from the University of Michigan, Ann Arbor, the M.S. degree from Massachusetts Institute of Technology, Cambridge, and the Ph.D. degree from the University of Michigan, all in electrical engineering, in 1969,1972 , and 1978 , respectively.

He was a Member of Technical Staff at Bell Telephone Laboratories, Holmdel, NJ, and was an Assistant Professor of Electrical Engineering at Michigan State University and the University of Michigan. He is the President of McCleer Power, Inc., Jackson, MI, a producer of prototype electrical machines and power electronic drives, where he designs and fabricates machines and drives for application in the energy, automotive, appliance, heating, ventilation, and air conditioning, and manufacturing industries. He is a consultant to the U.S. Army Tank and Automotive Command on electric drives for military vehicles. He is the holder of six U.S. patents on motors and drives.

Dr. McCleer is a Registered Professional Engineer in the State of Michigan.

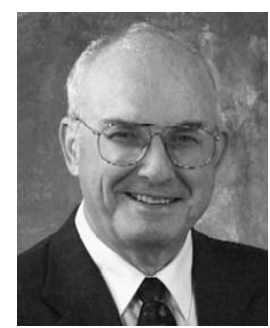

John W. McKeever received the B.S. degree from Case Institute of Technology, Cleveland, $\mathrm{OH}$, in 1960, and the M.S. and Ph.D. degrees from the University of Tennessee, Knoxville, in 1968 and 1973 , respectively, all in physics.

He has 45 years of work experience serving in technical and project management capacities at government-owned contractor-operated facilities in Oak Ridge, TN. From 1960 to 1970, he worked on barrier development for the gaseous diffusion process. Between 1970-1982, he designed and tested rotating machine components for the gas centrifuge developed at Oak Ridge for the U.S. Department of Energy (DOE). From 1982 to 1985, he managed the Machine and Balance of Plant Materials Group, during which time he chaired an advanced component development team. From 1985 to 1995, he transferred technology developed for the DOE to U.S. industry. During this time, he managed a superconducting motor project, a new soft-switched inverter development project, and a high-voltage dc transmission cost reduction project. Since 1995, he has managed hybrid electric vehicle projects to support the Department of Energy's Office of FreedomCAR and Vehicle Technologies and collaborative research projects with industry at Oak Ridge National Laboratory's Power Electronics and Electric Machinery Research Center, which is now located at Oak Ridge National Laboratory's new National Transportation Research Center in Knoxville, TN. He has authored 45 publications and three patents. 